\title{
Pengembangan Organisasi Menggunakan Open System Model
}

\author{
Mohammad Risqi, Luqman Tifa Perwira \\ Magister Psikologi Profesi, Fakultas Psikologi, Universitas Ahmad Dahlan, Indonesia

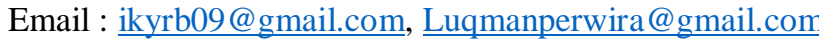

\begin{abstract}
Pt. PN is a company engaged in coal mining contractors. One of the vision \&mission of PT. PN is becoming a global top 8 company that has excellence in all fields. Business expansion is one of the company's agenda to become an excellent minning company in Indonesia. This research was conducted to identify and map problems in PT PN by using open system model diagnostic method and data collection with qualitative method. The results showed that there are problems in the HRM system, not optimal HRM system because the development program has not been optimal, so it has an impact on employee competence, competency problems then impact on employee readiness on the business expansion agenda. Mentoring program intervention at the deputy project manager level aims to assist the company in carrying out the development process in the company. The intervention of this mentoring program also supports the company's mission in improving the quality of human resources and preparing competent cadres for organizational sustainability.
\end{abstract}

Keyword:Open System Model;Organizational Development; Mentoring Program;

\begin{abstract}
Abstrak
PT.PN adalah perusahaan yang bergerak di bidang kontraktor penambangan batubara. Salah satu visi \& misi PT.PN adalah menjadi perusahaan top 8 global yang memiliki keunggulan di segala bidang. Ekspansi bisnis merupakan salah agenda perusahaan untuk menjadi perusahaan excellent minning di Indonesia. Penelitian ini dilakukan untuk mengindentifikasi dan memetakan permasalahan di PT PN dengan menggunakan metode diagnosa open system model dan pengumpulan data dengan metode kualitatif. Hasil penelitian menunjukan bahwa ada permasalahan pada sistem HRM, belum optimalnya sistem HRM dikarenakan program pengembangan belum optimal, sehingga berdampak pada kompetensi karyawan, permasalahan kompetensi kemudian berdampak pada kesiapan karyawan pada agenda ekspansi bisnis. Intervensi program mentoring pada level deputy project manager bertujuan untuk membantu perusahaan dalam menjalankan proses pengembangan di perusahaan. Intervensi program mentoring ini juga mendukung pada misi perusahaan dalam meningkatkan mutu SDM dan menyiapkan kader yang kompeten untuk keberlanjutan organisasi.
\end{abstract}

Kata Kunci:Open System Model; Pengembangan Organisasi; Program Mentoring;

\section{Pendahuluan}

PT.PN adalah perusahaan yang bergerak di bidang kontraktor penambangan batubara. PT.PN juga dipercaya mengerjakan tambang quarry, limestone, clinker, konstruksi bendungan dan konstruksi jalan. Saat ini PT PN memiliki lebih dari 10 anak perusahaan dan 17 distrik yang tersebar di wilayah Kalimantan, Sumatra dan Sumbawa. Dalam menjalankan operasi bisnisnya, perusahaan memiliki 3.556 unit produksi yang mencakup unit produksi utama maupun unit support dari kapasitas kecil hingga kapasitas besar. Selain itu perusahaan juga memiliki beberapa fasilitas penunjang seperti Coal stockpile dan Port Facilities dan memiliki fasilitas Central of Equipment Recondition (ERKA) \& Port Infrastructure yang berguna untuk menjalankan proses remanufacturing dan rekondisi unit alat berat perusahaan.

Salah satu visi \& misi PT.PN adalah menjadi perusahaan top 8 global yang memiliki keunggulan di segala bidang. Untuk mewujudkan tujuan tersebut organisasi menghadapi tantangan eksternal maupun internal di perusahaan. Cummings \& Worley [1] menyebutkan tantangan dari luar organisasi adalah tuntutan yang berasal dari luar lingkungan organisasi seperti kebijakan pemerintah, persaingan dengan organisasi lain dan lingkungan. Tantangan dari

Diterima Redaksi : 18-02-2021 | Selesai Revisi : 01-05-2021 | Diterbitkan Online : 03-05-2021 
dalam organisasi adalah yang hal-hal berkaitan dengan kebutuhan-kebutuhan organisasi dalam mencapai tujuan. Untuk dapat mewujudkan visi-misi harus mampu mengelola dan menyesuaikan dengan segala hal-hal yang berkaitan dengan tuntutan yang berasal dari internal dan eksternal organisasi

Tantangan eksternal yang dihadapi perusahaan pada sektor batu bara adalah adanya kewajiban pemerintah untuk memasok $25 \%$ produksi batu bara ke dalam negeri, ketidakpastian regulasi dan hukum sektor batu bara dan kebijakan negara China dalam menekan impor batu bara [2]. Ketidakpastian harga acuan batubara juga dapat mempengaruhi target produksi dan profit perusahaan. Meskipun demikian dalam menghadapi tantangan eksternal, perusahaan bergerak dalam menerapkan kebijakan-kebijakan ditubuh perusahaan seperti menekankan biaya (efisiensi) dengan menekan cost pengerukan dan memberikan diskon ketika harga batu bara sedang turun [3]

Berdasarkan data annual report pencapaian PT.PN ditahun 2018 menunjukkan kinerja yang positif. Hal ini terlihat pada laba perusahaan yang telah mengalami peningkatan sebesar $37 \%$. Peningkatan laba didapatkan dari sumbangsih penjualan sector batu bara, yaitu adanya peningkatan volume produksi batu bara sebesar $11 \%$. Atas pencapaian tersebut perusahaan mendapatkan apresiasi dari stakeholder dan konsumen berupa penghargaan tahunan.

Perkembangan bisnis yang dialami perusahaan di tahun 2018 menjadi peluang perusahaan untuk melakukan ekspansi bisnis di sector mineral lain. Menurut data dokumen, perusahaan telah melakukan akuisisi tambang emas Martabe di Sumatera Utara diakhir tahun 2018. Akuisi tambang emas merupakan bentuk nyata dari perluasan bisnis dan melihat peluang pasar kedepan [4]. Ekspansi bisnis merupakan salah agenda perusahaan dalam mewujudkan misi perusahaan sebagai excellent minning di Indonesia. Peluang melakukan ekspansi bisnis adalah strategi jangka panjang sehingga organisasi perlu mempersiapkan strategi pengembangan organisasi untuk mewujudkan tujuan jangka panjang. Oleh karena itu diperlukan upaya pengembangan organisasi atau organizational development (OD) di tubuh perusahaan untuk melihat pengembangan-pengembangan potensial yang dapat dilakukan organisasi untuk mewujudkan visi misi perusahaan

Cummings \& Worley [1] menyebutkan bahwa pengembangan organisasi atau organizational development (OD) merupakan implikasi dan transfer pengetahuan ilmu perilaku (behavioral science) yang mencakup pada system untuk pengembangan, perbaikan, dan penguatan secara terencana pada strategi, struktur, dan proses yang menghasilkan efektivitas organisasi. Brown \& Harvey [5] menjelaskan bahwa OD sebagai upaya dan program jangka panjang yang bertujuan untuk meningkatkan kemampuan organisasi untuk bertahan dengan mengatasi pemecahan atas masalah yang dihadapi dan perubahan yang terjadi Organisasi pada dasarnya akan terus berusaha berkembang. Oleh karena itu, pentingnya sebuah organisasi untuk melakukan pengembangan organisasi atau Organizational Development (OD).

Pengaplikasian pengembangan organisasi memiliki tahapan-tahapan yang dilalui para praktisi OD dan organisasi. Cummings dan Worley [1] mengatakan bahwa terdapat 4 tahapan dalam pengembangan organisasi yaitu Entering and Contracting, Diagnosing, Planning and Implementing Change, Evaluating and Instiutionalizing Change.

\section{Metode Penelitian}

Pada penelitian ini perlu dilakukan pemetaan mengenai kondisi dan gambaran permasalahan perusahaan, sehingga diperlukan proses asesmen dalam melihat permasalahan secara mendalam yang didukung dengan metode diagnosa yang tepat. Metode penelitian yang dilakukan menggunakan metode kualitatif dan metode yang digunakan untuk mendiagnosis perusahaan adalah open system model dari Cummings dan Worley. Model komprehensif untuk mendiagnosis sistem organisasi dengan open system model pada level organisasi meliputi inputs, design components dan outputs. 


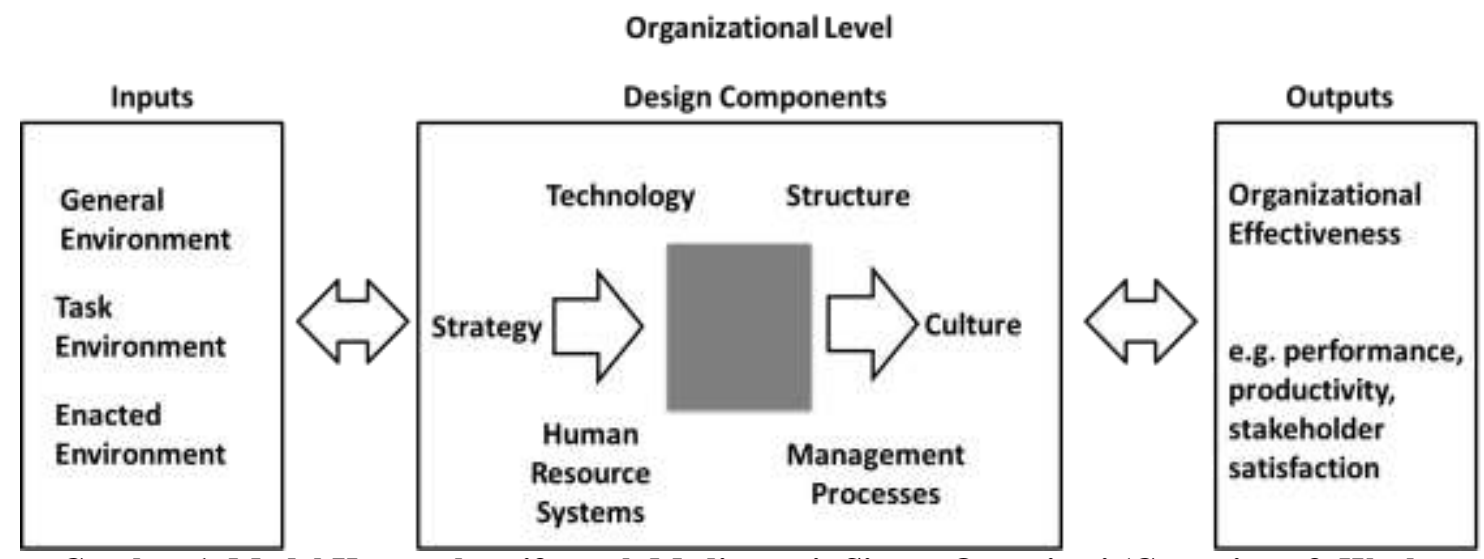

Gambar 1. Model Komprehensif untuk Mediagnosis Sistem Organisasi (Cummings \& Worley, 2015)

Pada proses analisa diagnosis organisasi, diperlukan pengambilan data yang bertujuan untuk menemukan permasalahan yang akan diungkap. Oleh sebab itu, ditentukan beberapa metode asesmen dalam penggalian data sebagai berikut:

1. Wawancara

Wawancara merupakan metode pengumpulan data dengan cara memberi pertanyaan langsung pada responden untuk memperoleh tujuan tertentu [6]. Diagnosis ini menggunakan wawancara dengan metode semi terstruktur (semi structure interview), yaitu jenis wawancara yang dalam pelaksanaannya ada guide atau pedoman wawancara namun pertanyaan ditanyakan secara semu atau bersifat lebih fleksibel dan dapat disesuaikan dengan kondisi [7]

2. Studi Dokumen

Studi dokumentasi merupakan teknik pengumpulan data yang tidak ditunjukan langsung kepada subyek penelitian. Dokumen yang diteliti dapat berbagai macam, tidak hanya dokumen resmi bisa berupa buku harian, surat pribadi, laporan, notulen rapat, catatan kasus (case record) dalam pekerjaan sosial, dan dokumen lainnya [8]. Studi dokumen dilakukan dengan tujuan menggali data tambahan yang dapat menguatkan kelengkapan data wawancara yang telah dilakukan sebelumnya. Pelaksanaan metode studi dokumen ini peneliti melakukan penelusuran data historis objek penelitian serta melihat sejauhmana proses yang berjalan telah terdokumentasikan dengan baik [9]..

\section{Observasi}

Observasi dilakukan secara partisipan dimana peneliti melakukan pengamatan secara langsung di perusahaan. Observasi partisipatif dilakukan agar data yang diperoleh lebih lengkap, tajam dan sampai mengetahui pada tingkat makna dari seriap perilaku yang nampak [8]. Hasil observasi dicatat secara naratif menggunakan anecdotal records dengan objek yang diobservasi dari perilaku karyawan dan kondisi perusahaan serta mengacu pada aspek diagnosa model open system yang dapat diamati.

Tabel 2. Matriks Diagnosa Organisasi

\begin{tabular}{lccc}
\hline \multirow{2}{*}{ Aspek } & \multicolumn{3}{c}{ Metode Asesmen } \\
\cline { 2 - 4 } Inputs & Wawancara & Studi Dokumen & Observasi \\
\hline General environment & $\sqrt{ }$ & $\sqrt{ }$ & \\
Task environment & $\sqrt{ }$ & & \\
Enacted environment & $\sqrt{ }$ & & $\sqrt{ }$ \\
\hline Design Components & & $\sqrt{ }$ & $\sqrt{ }$ \\
\hline Strategy & $\sqrt{ }$ & $\sqrt{ }$ & \\
Structure & $\sqrt{ }$ & $\sqrt{ }$ & \\
Human resouce systems & $\sqrt{ }$ & &
\end{tabular}

$\underline{\text { Psyche } 165 \text { Journal Terakredetasi Sinta } 5}$ 


\begin{tabular}{llcl} 
Management processes & $\sqrt{ }$ & & $\sqrt{ }$ \\
Technology & $\sqrt{ }$ & & $\sqrt{ }$ \\
Culture & $\sqrt{ }$ & & \\
\hline Outputs & & $\sqrt{ }$ & $\sqrt{ }$ \\
\hline Productivity & $\sqrt{ }$ & & $\sqrt{ }$ \\
Kondisi Keuangan & $\sqrt{ }$ & & \\
Stakeholder Satisfaction & $\sqrt{ }$ & $\sqrt{ }$ & \\
Human Outcome & $\sqrt{ }$ & $\sqrt{ }$ & \\
Subjective Outcome & $\sqrt{ }$ & & \\
\hline
\end{tabular}

\section{Hasil \& Pembahasan}

Situasi bisnis yang semakin dinamis dan adanya persaingan yang dihadapi perusahaan direspon dengan menerapkan corporate strategic plan 2019. Corporate startegic plan di tahun 2019 adalah meningkatkan keunggulan teknologi informasi, inovasi bisnis, efisiensi, kuantitas dan kualitas SDM, corporate culture hingga menyiapkan strategic plan jangka panjang.

Efisiensi merupakan salah satu misi perusahaan menghadapi situasi pasar yang tidak pasti. Efisien cost dilakukan perusahaan dengan menerapkan kebijakan remanufacturing, rejuvenil mesin untuk menambah usia penggunaan mesin, sebagai penghematan perusahaan pada kebutuhan armada baru. Langkah remanufacturing juga adalah langkah antisipasi perusahaan atas kebutuhan dan ketersediaan alat berat yang ditidak dapat dipenuhi supplyer. Langkah efisiensi operasional lainnya yaitu menerapkan kebijakan produksi bahan alat berat yang bisa diproduksi, serta membangun pabrik coal coaking sendiri.

Disamping adanya upaya efisiensi perusahaan memiliki misi mengisi kebutuhan SDM sesuai dengan kebutuhan MPP perusahaan. Perusahaan yang baru mengalami restrukturisasi akibat adanya promosi, mutasi, rotasi dan masuk keluarnya karyawan di organisasi, sedang mengalami kekosongan posisi di perusahaan. Hal ini kemudian menjadi acuan perusahaan menerapkan rekrutmen \& seleksi eskternal dan internal kebutuhan perusahaan. Permasalahan yang dirasakan saat ini kurangnya SDM berpengaruh terhadap beban kerja dan lembur pada karyawan. Selain itu karyawan yang mengalami rotasi jabatan dituntut untuk cepat beradaptasi dengan pekerjaannya dan mengembangan kompetensinya melalui program pengembangan yang diterapkan perusahaan. Berdasarkan hasil temuan evaluasi Training Need Analisys (TNA) yang dilakukan saat ini belum optimal dalam meningkatkan kompetensi karyawan. Hal ini disebabkan kurang berjalannya fungsi kontroling pengawasan TNA pada karyawan yang melibatkan atasan dan bawahan. Keterbatasan yang dirasakan karyawan adalah kesibukan karyawan pada target KPI dan membagi prioritas untuk mengikuti program training yang disediakan. Hal ini menjadi indikator terhambatnya proses pengembangan karyawan.

Selain efektivitas pengembangan pada karyawan, perusahaan berupaya meningkatkan kinerja karyawan dengan meningkatkan efektivitas internalisasi corporate value pada karyawan. Penerapan corporate value dilakukan dengan program-program disusun departemen corporate culture knowledge management. Tujuan dari corporate value adalah membudidayakan perilaku kerja agar terimplementasikannya enam nilai inti pada karyawan. Internalisasi enam nilai inti yang berlaku saat ini belum menyeluruh pada level operasional. Permasalahan pada level operasional yaitu kurangnya kesadaran karyawan dalam teknosaving, perilaku yang memicu terjadinya kecelakaan kerja. Terlihat pada angka kecelakaan kerja diperusahaan ditahun 2018 tergolong tinggi yaitu mencapai 504 kasus dari 152 kasus yang ditargetkan.

Visi perusahaan jangka panjang yaitu menjadi perusahaan excellent minning service. Kebijakan perusahaan saat ini adalah melakukan persiapan akan current bussines ke strategi jangka panjang perusahaan pada new bussiness. Strategi perluasan bisnis bermakna akan meningkatnya kebutuhan organisasi yang lebih besar. Sementara pada ratio benchstrenght perusahaan mengalami kekurangan karyawan talent untuk kebutuhan promosi. Permasalahan kurangnya kader di tubuh perusahaan disebabkan adanya permasalahan gap kompetensi pada posisi project

\section{$\underline{\text { Psyche } 165 \text { Journal Terakredetasi Sinta } 5}$}


manager dan deputy project manager. Gap kompetensi yang terjadi antara PM dan DPM akan menghambat upaya suksesi untuk kebutuhan perluasan bisnis. Terlebih posisi PM dan DPM merupakan posisi vital yang menjalankan fungsi operasional pada site/distrik perusahaan. Pengembangan kompetensi yang dilakukan diperusahaan umumnya adalah memberikan training untuk meningkatkan kompetensi karyawan, akan efektivitas training need analysis yang dilakukan kurang dapat berjalan dengan maksimal. Hal ini disebabkan kurangnya fungsi pengawasan antara atasan dan bawahan, kurang berfungsinya pengawasan disebabkan budaya, iklim organisasi, kedekatan antara atasan dan bawahan di organisasi.

Berdasarkan hasil asesmen pendekatan open system. Ditemukan beberapa permasalahan yang dapat menghambat efektivitas organisasi yaitu adanya gap kompetensi pada posisi Project Manager (PM) \& Deputy Project Manager (DPM) yang berdampak pada terhambatnya kesiapan kaderisasi. Hal ini menjadi potensial problem yang akan menghambat laju perusahaan sebagai organisasi yang efektif dan efisien kedepan.

Fokus permasalahan yang menjadi sasaran intervensi adalah permasalahan kompetensi pada posisi project manager (PM) dan deputy project manager (DPM). PM dan DPM merupakan posisi penting yang menjalankan operasional bisnis di site tambang PT.PN. Kurangnya SDM yang kompeten ditubuh organisasi akan menghambat kebutuhan organisasi akan perluasan bisnis.

Perluasan bisnis merupakan salah satu strategi perusahaan untuk menyiapkan organisasi ke arah excellent minning plan. Untuk melakukan perluasan bisnis, organisasi mengalami peningkatan kebutuhan SDM . Berdasarkan hasil evaluasi benchstrenght pada posisi PM dan DPM, kesiapan kader untuk kebutuhan ekspansi bisnis, organisasi mengalami krisis kader yaitu 1: 0.69. Artinya perusahaan belum memiliki kader yang ideal dan siap untuk dipromosikan di distrik baru. Padahal untuk melakukan ekspansi bisnis organisasi akan membutuhkan ketersediaan PM dan DPM yang berkualitas.

Permasalahan kaderisasi pada posisi PM dan DPM disebabkan oleh gap kompetensi yang terjadi pada karyawan. Padahal kompetensi adalah faktor yang menentukan kemampuan individu dalam menyelesaikan pekerjaan. Karyawan yang belum kompeten akan kesulitan dan tidak tahan menghadapi tugas-tugas pekerjaannya. Kompetensi karyawan akan menentukan kinerja yang dihasilkan karyawan [10]. Berdasarkan hasil wawancara, pengembangan kompetensi yang disorot pada posisi PM dan DPM adalah kompetensi teknis dan leadership.

Kurang berkembangnya kompetensi teknis dan leadership pada PM dan DPM disebabkan kurang optimalnya agenda pengembangan yang diterapkan di organisasi. Faktor yang menghambat proses pengembangan yang dilakukan organisasi adalah kesempatan karyawan dalam mengikuti program training, proses evaluasi training yang dilakukan, kerja sama antara bawahan dan atasan dalam mengelola kebutuhan pengembangan karyawan. Kurang berjalannya fungsi pengawasan yang dipengaruhi sejauhmana interaksi antara antara atasan dan bawahan, minimnya dapat disebabkan orientasi individu, pola komunikasi, perbedaan (generasi, latar belakang, usia) dan persepsi pada inidividu. Selain itu budaya dan iklim organisasi yang terbangun di organisasi juga mempengaruhi interaksi yang terjadi antara karyawan [11]. Organisasi perlu menyadari peran leader di organisasi bukan hanya mengarahkan organisasi pada visi misi dan tujuan organisasi, lebih dari itu peran leader adalah melakukan dan melakukan transfer knowledge di organisasi untuk kebutuhan pengembangan organisasi yang berkelanjutan.

Agenda development yang sejauh ini dilakukan berupa kegiatan coaching, counseling, mentoring \& training. Namun development program yang dilakukan perusahaan ditahun-tahun sebelumnya terlalu berfokus pada program pelatihan. Disisi lain efektivitas pelatihan yang dijalani sejauh juga belum sepenuhnya berjalan efektif. Hal ini menjadi pertimbangan bagi organisasi untuk menerapkan program pengembangan yang lebih spesifik untuk memenuhi kebutuhan kompetensi teknis dan leadership pada karyawan. Terlebih orientasi perusahaan ditahun ini adalah meningkatkan keunggulan SDM pada posisi PM dan DPM.

Berdasarkan asesmen yang dilakukan, kebutuhan organisasi saat ini adalah mempersiapkan PM dan DPM dari segi kompetensi teknis dan leadership. Oleh karena itu 
penulis menyarankan intervensi penyusunan program mentoring pada posisi Deputy Project Manager, kegiatan ini diharapkan dapat memenuhi kebutuhan pengembangan talent manajemen di organisasi secara berkelanjutan. Penelitian dari Hamdani [12] membuktikan talent management yang dilakukan organisasi berdampak positif terhadap pengembangan karir karyawan. Oleh sebab itu intervernsi penyusunan panduan program mentoring merupakan salah satu upaya penulis dalam membuntu perusahaan dalam memenuhi upaya pengembangan karyawan di perusahaan

\section{Kesimpulan}

Berdasarkan hasil temuan dan diagnosa Organizational Development (OD) yang dilakukan, sistem HRM yang dijalankan perusahaan belum optimal dikarenakan pengembangan yang diterapkan belum optimal, sehingga berdampak pada kompetensi karyawan, serta kurangya kompetensi berdampak pada kaderisasi perusahaan.

Permasalahan kaderisasasi akan menghambat laju organisasi dalam melakukan ekspansi bisnis. Hal ini mendorong perusahaan untuk melakukan percepatan atau akselerasi development program pada karyawan. Tujuannya adalah untuk meningkatkan kebutuhan karyawan dari segi kompetensi. Oleh karena itu penulis menyarankan intervensi penyusunan program mentoring pada level deputy projecr manager. Panduan ini bertujuan untuk membantu perusahaan dalam menjalankan proses pengembangan di perusahaan. Program mentoring ini juga mendukung pada misi perusahaan dalam meningkatkan SDM dan menyiapkan kader kompeten untuk keberlanjutan organisasi.

Penyusunan panduan program mentoring yang terencana akan membantu perusahaan dalam menjalankan fungsi pengelolaan sumber daya manusia yang lebih efektif dan terukur. Program mentoring adalah bentuk talent management terhadap pengembangan karir individu di organisasi.

\section{Daftar Pustaka}

[1] T. G. \& W. C. G. Cummings, Organizational Development \& Change, 10th ed. Stanford USA: Cengage Learning, 2015.

[2] F. Sulmaihati, "Prospek Bisnis Batu Bara 2019: Kepastian Hukum Jadi Tantangan Utama," Jan. 01, 2019.

[3] P. Ika, "Pamapersada Nusantara tambah 700 unit alat berat pada 2018," May 27, 2018.

[4] I. P, "Usai akuisisi Martabe, Pamapersada Nusantara akan lakukan eksplorasi tambang emas," Oct. 03, 2018.

[5] B. D. \& H. D. R, And Experiential Approach Too Organizational Development (7th edition). New Delhi: Person Education, 2006.

[6] E. Poerwandari, Pendekatan Kualitatif Untuk Penelitian Perilaku Manusia. Jakarta: LPSP3 Universitas Indonesia, 2009.

[7] L. J. Moelong, Metodologi Penelitian Kualitatif. Bandung: PT.Remaja Rodaskarya, 2007.

[8] Sugiyono, Metode Penelitian Kuantitatif, Kualitatif dan $R \&$ D . Bandung: Alfabeta, 2013.

[9] J. W. Creswell, Riset Design Pendekatan Kualitatif, Kuantitatif Dan Mixed. Yogyakarta: Pustaka Pelajar, 2014.

[10] Z. Ismail, R. Abidin, "Impact of Workers Competency On Their Performances in The Malaysian Private Service Sector," Bussiness Econ. Horizonz, vol. 2, no. 2, pp. 25-36, 2010.

[11] R. M. Steers, “Antecendent and Outcomes Organizational Commitment," vol. 1, no. 22, pp. 4656., 1977.

[12] Irmawaty and M. Hamdani, "Pengaruh talent management terhadap pengembangan karir Pegawai di Universitas Terbuka," J. Organ. dan Manaj., vol. 12, no. 2, pp. 97-104, 2016. 